\title{
EDITORIAL
}

\section{The ethical challenge of surgical innovation}

\author{
Paulo Palma • Tomas Rosenbaum
}

Received: 2 January 2009 / Accepted: 25 January 2009 / Published online: 14 February 2009

(C) The International Urogynecological Association 2009

A philosophical view regarding technical progress in surgery states that "there is no control on surgical innovation outside of the realm of the surgeon's own ethical and moral compass" [1].

On the other hand, creative surgeons as opposed to other artists must be guided by clinical common sense.

The driving force behind innovation these days is not only the reduction of recurrence and death but also the decrease of morbidity rates.

Minimally invasive synthetic slings such as the tensionfree vaginal tape replaced the Burch colposuspension for the treatment of urinary stress incontinence and, in the last decade, have become the preferred technique for the surgical treatment of this condition [2].

Various factors contributed to the popularization of synthetic slings, amongst them, the fact that techniques like the Pereira's needle suspension and all its variants did not stand the test of time.

However, minimally invasive slings brought with them a series of new complications, both related to the tape itself and to the insertion techniques. Some of these have even shown to be potentially lethal [3].

With the retro-pubic technique, most of the major complications are related to the blind nature of the passage of the needles close to major vessels [4]. Bleeding upon

P. Palma $(\bowtie)$

Universidade Estadual de Campinas,

Sao Paulo, Brazil

e-mail: ppalma@uol.com.br

T. Rosenbaum

Department of Surgery, Ealing Hospital,

Uxbridge R, Southall,

Middlesex UB1 3HW, UK entry of the retro-pubic space and the proximity of the femoral vessels have been shown to be real serious risks.

The trans-obturator technique is associated with a lower incidence of vascular as well as bladder and urethral injuries. The latter are reported to occur in less than $1 \%$ of patients and, as usual, occur more frequently during the learning curve of the procedure. However, the passage of the needles is still blind although the terrain is less dangerous.

To try to reduce the risks even further, the technique of placing the sub-urethral tape anchored laterally to the obturator internus muscles at the level of the tendineous arches was described. This should eliminate totally the risk of injury of a major vessel or the bladder [5].

All of these are, no doubt, remarkable achievements. But, needless to say, even minimally invasive procedures require a learning period. In addition, treatment failure is also an important complication.

And how about new products being introduced into the market with no significant experimental data and no clinical trials at all?

And what about publications with a mean follow-up of as short as 2 months [6]?

The introduction of meshes and kits for the management of pelvic organ prolapse is another important issue. The classical repair for the treatment of anterior vaginal prolapse does not stand the test of time in a certain subset of patients. Trans-obturator anchored meshes may be the future but need very careful evaluation [7].

Ethical dilemmas always appear when new devices developed in the laboratory are transferred to the bedside. Regulatory agencies such as the Food and Drug Administration in United States are more flexible with new devices than with drugs.

In fact, some meshes are approved by similarity with no clinical trial at all. 
Surgical techniques are evolving processes, and innovations occur all the time and should be encouraged and welcomed.

But which are the minimal requirements that should be satisfied before we jump on the bandwagon?

These are complex and subtle issues about which there is no single answer and it is very difficult to reach a consensus.

We know that the Institutional Review Boards do their homework, but it is not enough; members of such local boards may not be familiar with the leading-edge technology in the field.

To wait for level I evidence-based studies would be desirable, but is hardly realistic: The time required is very long, and costs involved in this process are very high.

As for us, all these devices should be considered experimental and restricted to academic protocols until large case series with at least 1-year follow-up is available.

How can specialty societies help?

Societies should play a major role working on guidelines, defining minimum follow-up before publishing the initial series of patients, selecting acceptable studies, and stimulating publications of data, including complications [8].

These actions would help to improve the standards of surgical innovation.

\section{References}

1. Reiter-Theil S, GJ Agich (2006) Research on clinical ethics and consultation. Introduction to the theme. Med health care Plilos 1:35

2. Ulmsten U, Henriksson L, Johnson P, Varhos G (1996) An ambulatory surgical procedure under local anesthesia for treatment of female urinary incontinence. Int Urogynecol J 7:81-86

3. Bafghi A, Iannelli A, Trastour C, Bernard A, Bongain A, Gigenheim J (2005) Bowel perforation as late complication of tension-free vaginal tape. J Gynecol Obstet Biol Reprod 34(6):606607

4. Petros PE, Richardson PA (2005) Miduretral tissue fixation system sling - a micromethod for cure of stress incontinence-preliminary report. Aust N Z J Obstet Gynaecol 45:372-375

5. Palma P, Riccetto C, Reges R, Fraga R, Miyaoka R, Herrmann V, Marcondes $\mathrm{T}$ (2008) Arcus to arcus microsling: technique and preliminary results. Int Urogynecol J 19:1133-1136

6. Solà DV, Ricci AP, Pardo SJ (2008) Stress urinary incontinence surgical correction with third generation sub-mid-urethral sling. TVT-Secur Actas Urol Esp 32:522-529

7. Palma P, Riccetto C, Muller V, Fraga R, Contreras O, Sarsotti C, Paladini M, Cianci A, Barthos P (2007) Nazca: a monoprosthesis for the simultaneous correction of cystocele and urinary stress incontinence - a multicentric trial. Urology 70(3S):193-194

8. Deng YD, Rutman M, Raz S, Rodriguez L (2007) Presentation and management of major complications of midurethral slings: are complications under-reported? Neurology and Urodymanics 52:2646 